\title{
Functional diversity in the color vision of cichlid fishes
}

Shai Sabbah", Raico Lamela Laria ${ }^{1}$, Suzanne M Gray ${ }^{1,2}$, Craig W Hawryshyn ${ }^{1,3^{*}}$

\begin{abstract}
Background: Color vision plays a critical role in visual behavior. An animal's capacity for color vision rests on the presence of differentially sensitive cone photoreceptors. Spectral sensitivity is a measure of the visual responsiveness of these cones at different light wavelengths. Four classes of cone pigments have been identified in vertebrates, but in teleost fishes, opsin genes have undergone gene duplication events and thus can produce a larger number of spectrally distinct cone pigments. In this study, we examine the question of large-scale variation in color vision with respect to individual, sex and species that may result from differential expression of cone pigments. Cichlid fishes are an excellent model system for examining variation in spectral sensitivity because they have seven distinct cone opsin genes that are differentially expressed.

Results: To examine the variation in the number of cones that participate in cichlid spectral sensitivity, we used whole organism electrophysiology, opsin gene expression and empirical modeling. Examination of over 100 spectral sensitivity curves from 34 individuals of three species revealed that (1) spectral sensitivity of individual cichlids was based on different subsets of four or five cone pigments, (2) spectral sensitivity was shaped by multiple cone interactions and (3) spectral sensitivity differed between species and correlated with foraging mode and the spectral reflectance of conspecifics. Our data also suggest that there may be significant differences in opsin gene expression between the sexes.

Conclusions: Our study describes complex opponent and nonopponent cone interactions that represent the requisite neural processing for color vision. We present the first comprehensive evidence for pentachromatic color vision in vertebrates, which offers the potential for extraordinary spectral discrimination capabilities. We show that opsin gene expression in cichlids, and possibly also spectral sensitivity, may be sex-dependent. We argue that females and males sample their visual environment differently, providing a neural basis for sexually dimorphic visual behaviour. The diversification of spectral sensitivity likely contributes to sensory adaptations that enhance the contrast of transparent prey and the detection of optical signals from conspecifics, suggesting a role for both natural and sexual selection in tuning color vision.
\end{abstract}

\section{Background}

Vision is central to the survival of animals. Visual cues are used for orientation, detecting prey, avoiding predators and communication. The visual process starts with visual pigments absorbing light and initiating a photochemical cascade that leads to neural signaling, perception and ultimately visually mediated behavior. A common method for studying vision is the measurement of spectral sensitivity. Spectral sensitivity is the relative efficiency of detection of light as a function of

\footnotetext{
* Correspondence: craig.hawryshyn@queensu.ca

'Department of Biology, Queen's University, Kingston, ON, K7L 3N6, Canada Full list of author information is available at the end of the article
}

wavelength. Spectral sensitivity is used to describe the characteristics of visual pigments found in cone photoreceptors in the retina, and it is particularly useful in describing the mechanisms of color vision $[1,2]$.

Comparative studies in vertebrates established the presence of four spectrally distinct classes of cone visual pigments produced by several different opsin genes: SWS1 being the ultraviolet/violet-sensitive class (355$440 \mathrm{~nm}$ ), $S W S 2$ being the short wavelength-sensitive class (410-490 $\mathrm{nm}$ ), RH2 being the mid-wavelengthsensitive class (470-530 nm) and LWS being the long-wavelength-sensitive class (495-570 $\mathrm{nm}$ ) [3,4]. These opsin genes have been identified in the earliest 
vertebrate lineage, the jawless fishes or Agnathans (lamprey) [5], and arose through duplications of a single ancestral opsin gene. Mutations in duplicated genes can lead to the evolution of additional spectral classes of cone visual pigments within a class of opsin gene. In fact, in many teleost fishes, cone opsin genes have undergone gene duplication to produce a wide range of opsin genes [6-8]. The expression of different subsets of these genes can potentially generate large-scale variation in spectral sensitivity and the mechanisms of color vision in fish [9-11].

The cichlid fishes of Lake Malawi are an excellent model system for examining large-scale variation in color vision. Lake Malawi has 700-800 species of cichlids [12-14] that have evolved from a common ancestor in a brief period of evolutionary time (2-4 million years) [15]. Malawi cichlids are notable for their diversity in male nuptial color patterns, sexual dimorphism in color patterns and visual communication processes governing mate choice [16-18]. Cichlids have undergone multiple opsin gene duplication events, producing seven classes of cone opsin genes $[10,19]$. These seven opsin genes include an ultraviolet-sensitive (SWS1), two short-wavelength-sensitive (SWS2a and

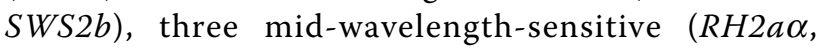
$R H 2 a \beta, R H 2 b)$ and long-wavelength-sensitive ( $L W S)$ cone opsins. Of particular interest is that Malawi cichlids show differential expression of primarily three of the seven available cone opsin genes [9,20,21], with some evidence of differential expression through ontogeny [20]. This raises an intriguing question of how seven opsin genes are maintained in Malawi cichlids. Our central research focus concerns the large-scale diversity in cichlid visual systems and differences in the number of cone classes that participate in color vision. Here we examine variation in cone classes contributing to spectral sensitivity in cichlids between individuals, sexes and species and discuss the adaptive significance of this variation in color vision.

\section{Results}

To quantify the number of physiologically functional cone classes, we recorded electroretinograms (ERG) from whole fish preparations of three Malawi cichlids: Metriaclima zebra, Melanochromis auratus and Protomelas taeniolatus. We measured the $b$-wave amplitude of ERGs, representative of ON (response to light stimulus onset) bipolar cell activity, to assess the integrative response of functional cones. We were primarily interested in evaluating the number of cone classes contributing to spectral sensitivity and their corresponding visual pigments, but we also used multiple-mechanism modeling to understand the opponent and nonopponent cone interactions at play that can shape the spectral tuning of cone mechanisms. Our analysis was focused on describing variation in spectral sensitivity with respect to individual, sex and species differences.

\section{Individual differences in spectral sensitivity}

Over 100 spectral sensitivity curves were recorded from a total of 15 females and 19 males of the three species studied. The spectral sensitivity of each individual was evaluated under three different color background conditions, each aimed at isolating the sensitivity of specific cones (Figure 1; see Additional file 1 for the background conditions and the quantum catches of the various cone mechanisms). For each individual, we identified the number of sensitivity peaks and their spectral locations for the three background conditions. We then fitted cone pigment absorption templates [22] to the sensitivity peaks using a least-squares method.

Individuals of all three species of Malawi cichlids examined in this study possessed 11 different cone subsets (Table 1; see Table 2 for specific $\lambda_{\max }$ values and goodness of fit of visual pigment templates). A maximum of five different cone classes were present in $41 \%$ of fish, four different cone classes were present in 56\% of fish, and three different cone classes were present in only $3 \%$ of the fish (one individual) (Table 1). All cone subsets (excluding no. 5) consisted of at least two pigments corresponding to single cones and two pigments corresponding to double cones.

Examining the individuals of each species separately revealed that all individuals in $M$. zebra possessed four cone pigments, while $55 \%$ of individuals in $M$. auratus and $67 \%$ of individuals in P. taeniolatus possessed five cone pigments (Table 1 ).

The collection of all cone subsets exhibited by either $M$. auratus or P. taeniolatus included the complete opsin gene set (Table 1). That is, each of these species utilizes the complete set of six cone pigments (RH2a $\alpha$ and $\mathrm{RH} 2 \mathrm{a} \beta$ pooled because of genetic and functional similarity $[10,19])$. However, the collection of all subsets exhibited by M. zebra encompassed only five cone pigments and excluded the LWS pigment.

\section{Sex differences in spectral sensitivity}

To evaluate how sex differences contribute to the variation in cone subsets, we calculated the frequency of cone subsets in each species and sex. In all species, the individual variation in pigment subsets used was high, and a strong trend for differences between females and males in the identity and frequency of the pigment subsets they utilized emerged (Table 3 ). The degree to which pigment subsets were shared between sexes varied across species. Half of $M$. zebra females shared subset 2 with all conspecific males, $28 \%$ of $M$. auratus males shared subset 3 with half the females and $60 \%$ of 


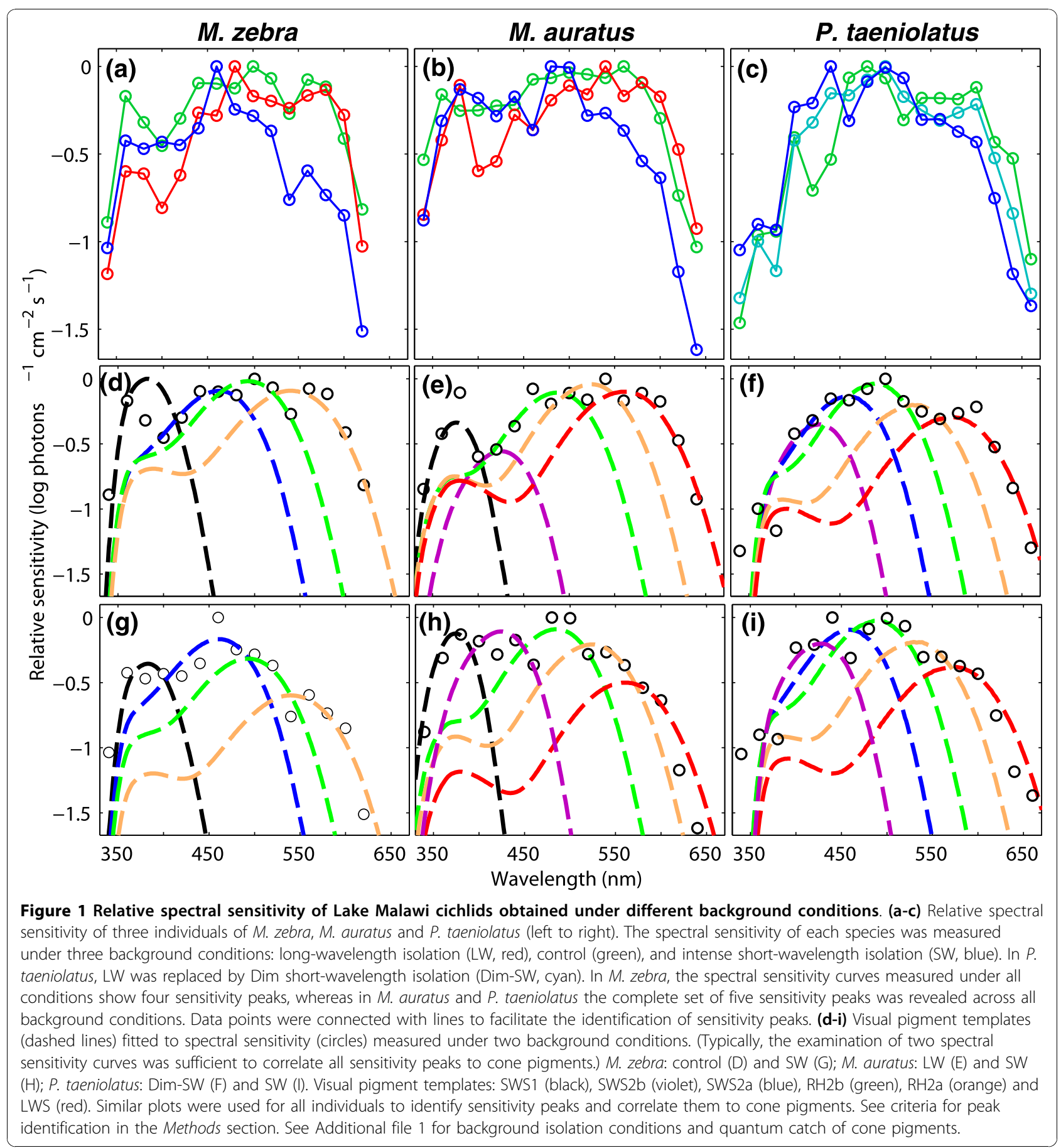

P. taeniolatus females shared subsets 6 and 7 with $71 \%$ of males.

The frequency of each cone pigment present in females and males was calculated (Figure 2). Sex differences in the frequency of cone pigments were evident in all species, with $M$. auratus and M. zebra showing the largest differences. The frequency of $M$. auratus females showing SWS1 pigments was $75 \%$ larger than in males, while the frequency of males showing SWS2a and LWS pigments was $71 \%$ and $100 \%$ larger than in females, respectively. The frequency of $M$. zebra males showing SWS2a cone pigment was $100 \%$ larger than in females, while SWS2b cone pigment was found only in females. In contrast, the frequency of cone pigments in P. taeniolatus showed less variation across sexes, with pigment frequencies differing $12 \%-42 \%$ between sexes. 
Table 1 Cone pigment subsets exhibited by the cichlid species examined

\begin{tabular}{|c|c|c|c|c|c|c|c|c|c|c|}
\hline & \multirow[t]{2}{*}{ Subset } & \multirow[t]{2}{*}{ Individuals } & \multicolumn{6}{|c|}{ Visual pigment } & \multirow[t]{2}{*}{ Cones } & \multirow[t]{2}{*}{ Frequency (\%) } \\
\hline & & & SWS1 & SWS2b & SWS2a & $\mathrm{RH} 2 \mathrm{~b}$ & $\mathrm{RH} 2 \mathrm{a}$ & LWS & & \\
\hline \multirow[t]{2}{*}{ M. zebra } & 1 & 3 & $382 \pm 1$ & 427 & & $492 \pm 2$ & $537 \pm 3$ & & 4 & 27.3 \\
\hline & 2 & 8 & $380 \pm 4$ & & $460 \pm 2$ & $490 \pm 4$ & $535 \pm 7$ & & 4 & 72.7 \\
\hline \multirow[t]{7}{*}{ M. auratus } & 3 & 4 & 374 & 424 & & 485 & 525 & 561 & 5 & 36.4 \\
\hline & 4 & 1 & 380 & & 463 & 494 & 543 & & 4 & 9.1 \\
\hline & 5 & 1 & & 429 & & 497 & 547 & & 3 & 9.1 \\
\hline & 6 & 1 & 374 & & 457 & 485 & 525 & 561 & 5 & 9.1 \\
\hline & 7 & 1 & & 424 & 457 & 485 & 526 & 562 & 5 & 9.1 \\
\hline & 8 & 2 & & 424 & & 485 & 525 & 561 & 4 & 18.2 \\
\hline & 9 & 1 & & & 457 & 485 & 525 & 561 & 4 & 9.1 \\
\hline \multirow[t]{5}{*}{ P. taeniolatus } & 6 & 3 & $379 \pm 1$ & & 457 & $488 \pm 3$ & $530 \pm 2$ & $567 \pm 8$ & 5 & 25.0 \\
\hline & 7 & 5 & & 428 & 457 & $489 \pm 2$ & $532 \pm 2$ & $574 \pm 3$ & 5 & 41.7 \\
\hline & 9 & 2 & & 428 & 457 & $487 \pm 1$ & & $567 \pm 6$ & 4 & 16.7 \\
\hline & 10 & 1 & & 428 & 457 & 494 & & 571 & 4 & 8.3 \\
\hline & 11 & 1 & & 428 & 457 & & 529 & 571 & 4 & 8.3 \\
\hline
\end{tabular}

In total, 11 different subsets of cone pigments were identified across the species studied. The number of individuals that exhibited each pigment subset, the number of cone classes included in each subset and the frequency of each cone pigment subset per species are indicated. The $\lambda_{\text {max }}$ (nm) values of cone pigments that comprised each subset are given (means \pm SD).

We also examined the effect of sex on the pattern of cone opsin gene expression. We focused our analysis on $M$. auratus and $P$. taeniolatus, the species that exhibited the lowest and highest degree of common cone pigment subsets between the sexes, respectively. Variation in opsin gene expression between females and males in $M$. auratus was larger than in P. taeniolatus (Figure 3). Specifically, in $M$. auratus, the expression of $R H 2 b$ and $R H 2 a$ opsin genes differed across sexes ( $t$-test, $d f=8, P<$ 0.0002 and $P<0.005$, respectively). In contrast, in $P$. taeniolatus, no significant differences in the relative opsin gene expression were detected between sexes $(t$-test, $P>$ 0.2 for all genes). See Additional file 2 for detailed $t$-test results and Additional file 3 for primer specifications for cone opsin genes. The frequency of cone pigments and opsin gene expression are not quantitatively comparable. In the calculation of pigment frequency, each individual is scored as either 1 (pigment present) or 0 (pigment absent), whereas gene expression can assume any value between 0 and 1 . Moreover, the expression level of an opsin gene does not necessarily dictate its contribution to sensitivity, since patterns of convergence of cones onto retinal interneurons and the network processing of these neurons [23] are critical to governing visual responsiveness. Our results show that females and males differ in the cone opsin gene expression profiles. Our results also suggest that females and males differ in cone pigment subsets and in the frequency of cone pigments. However, owing to sample size limitation imposed by the complexity of spectral sensitivity measurements, the statistical significance of the sex differences observed in cone pigment subsets and in the frequency of cone pigments cannot be evaluated at this time. It is important to note, however, that the variability of all three properties of the visual system of cichlids was consistently larger in $M$. auratus than in the other two species.

\section{Species differences in spectral sensitivity}

In general, different cichlid species used different cone subsets (Table 3). Closer examination reveals that females of the three species did not use the same cone subsets, but $43 \%$ of male $M$. auratus shared three cone subsets with $P$. taeniolatus males.

The frequency of cone pigments varied across species (Figure 4a). The frequency of RH2a $(\mathrm{SD}=14 \%)$ and RH2b $(\mathrm{SD}=5 \%)$ showed the smallest variation and did not differ significantly between species (Fisher's exact test; $P=0.091$ and $P=1$, respectively). In contrast, the frequency of LWS $(\mathrm{SD}=53 \%)$ and SWS1 $(\mathrm{SD}=38 \%)$ showed the largest variation and differed significantly between species (Fisher's exact test; $P<0.001$ for both pigments). See Figure 4 caption for detailed statistics. The frequency of SWS1 was highest in M. zebra (100\%), lower in M. auratus (54\%) and lowest in P. taeniolatus (25\%). The frequency of LWS in P. taeniolatus (100\%) and $M$. auratus (81\%) was higher than in M. zebra (0\%).

The frequency of the SWS1 cone pigment across species qualitatively correlated with planktivory. M. zebra may be highly planktivorous, feeding on both phytoplankton (mainly diatoms) and zooplankton (Cladocerans and copepods) [24]. M. auratus is omnivorous, consuming algae and a wide range of nonalgal dietary items such as cyclopoid copepods [24,25]. P. taeniolatus is almost strictly herbivorous and feeds on the biocover 
Table 2 Statistics of visual pigment templates fit to spectral sensitivity curves

\begin{tabular}{|c|c|c|c|c|c|c|c|c|c|c|c|c|}
\hline & \multirow[t]{2}{*}{ Gender } & \multirow[t]{2}{*}{ Fish ID } & \multicolumn{6}{|c|}{ Visual pigment template $^{a}$} & \multirow[t]{2}{*}{$A_{2} \%^{b}$} & \multirow[t]{2}{*}{$1^{\text {st }} R^{2 c}$} & \multirow[t]{2}{*}{$2^{\text {nd }} R^{2 d}$} & \multirow[t]{2}{*}{ Subset $^{\epsilon}$} \\
\hline & & & SWS1 & SWS2b & SWS2a & $\mathrm{RH} 2 \mathrm{~b}$ & $\mathrm{RH} 2 \mathrm{a}$ & LWS & & & & \\
\hline \multirow[t]{11}{*}{ M. zebra } & Female & ZF7 & $381(0.62)$ & $427(0.63)$ & & $491(0.76)$ & $535(0.90)$ & & 37.6 & RH2a (0.98) & LWS (0.47) & 1 \\
\hline & & ZF6 & $381(0.46)$ & $427(0.82)$ & & $491(0.70)$ & $535(0.90)$ & & 37.6 & $\mathrm{RH} 2 \mathrm{a}(0.98)$ & LWS (0.21) & 1 \\
\hline & & ZF8 & $383(0.88)$ & $428(0.55)$ & & $494(0.73)$ & $540(0.87)$ & & 53.8 & $\mathrm{RH} 2 \mathrm{a}(0.94)$ & LWS (0.59) & 1 \\
\hline & & ZF1 & $383(0.09)$ & & $461(0.96)$ & $493(0.72)$ & $540(0.85)$ & & 48.4 & $\mathrm{RH} 2 \mathrm{a}(0.95)$ & LWS (0.58) & 2 \\
\hline & & ZF4 & $379(0.91)$ & & $459(0.30)$ & $487(0.69)$ & $530(0.94)$ & & 21.5 & $\mathrm{RH} 2 \mathrm{a}(0.93)$ & LWS (0.01) & 2 \\
\hline & & ZF2 & $375(0.53)$ & & $461(0.98)$ & $493(0.38)$ & $540(0.96)$ & & 48.4 & $\mathrm{RH} 2 \mathrm{a}(0.95)$ & LWS (0.56) & 2 \\
\hline & Male & ZM2 & $375(0.85)$ & & $457(0.76)$ & $484(0.85)$ & $526(0.91)$ & & 8 & $\mathrm{RH} 2 \mathrm{a}(0.89)$ & LWS (0.49) & 2 \\
\hline & & ZM6 & $378(0.75)$ & & $458(0.57)$ & $487(0.81)$ & $530(0.95)$ & & 18.8 & $\mathrm{RH} 2 \mathrm{a}(0.97)$ & LWS $(-0.18)$ & 2 \\
\hline & & ZM4 & $383(0.15)$ & & $463(0.64)$ & $494(0.54)$ & $540(0.91)$ & & 53.7 & RH2a (0.99) & LWS (0.62) & 2 \\
\hline & & ZM1 & $385(0.55)$ & & $463(0.99)$ & $495(0.93)$ & $544(0.55)$ & & 59.1 & $\mathrm{RH} 2 \mathrm{a}(0.91)$ & LWS (0.64) & 2 \\
\hline & & ZM3 & $378(0.69)$ & & $458(0.18)$ & $487(0.91)$ & $530(0.79)$ & & 18.8 & $\mathrm{RH} 2 \mathrm{a}(0.91)$ & LWS (-0.69) & 2 \\
\hline \multirow[t]{11}{*}{ M. auratus } & Female & AF13 & $374(0.84)$ & $424(0.70)$ & & $485(0.82)$ & $525(0.72)$ & $561(0.87)$ & 0 & LWS (0.85) & & 3 \\
\hline & & AF15 & $374(0.25)$ & $424(0.75)$ & & $485(0.43)$ & $525(0.14)$ & $561(0.82)$ & 0 & LWS (0.85) & & 3 \\
\hline & & AF14 & $380(0.76)$ & & $463(0.33)$ & $494(0.81)$ & $543(0.71)$ & & 53.7 & $\mathrm{RH} 2 \mathrm{a}(0.91)$ & LWS (0.24) & 4 \\
\hline & & AF11 & & $429(0.47)$ & & $497(0.63)$ & $547(0.91)$ & & 64.5 & $\mathrm{RH} 2 \mathrm{a}(0.94)$ & LWS (0.84) & 5 \\
\hline & Male & AM14 & $374(0.71)$ & $424(0.96)$ & & $485(0.41)$ & $525(0.70)$ & $561(0.85)$ & 0 & LWS (0.96) & & 3 \\
\hline & & AM13 & $374(0.67)$ & $424(0.60)$ & & $485(0.73)$ & $525(0.74)$ & $561(0.85)$ & 0 & LWS (0.85) & & 3 \\
\hline & & AM12 & $374(0.54)$ & & $457(0.85)$ & $485(0.41)$ & $525(0.27)$ & $561(0.98)$ & 0 & LWS (0.98) & & 6 \\
\hline & & AM11 & & $424(0.32)$ & $457(0.09)$ & $485(0.85)$ & $526(0.43)$ & $562(0.57)$ & 3 & LWS (0.89) & & 7 \\
\hline & & AM16 & & $424(0.56)$ & & $485(0.41)$ & $525(0.47)$ & $561(0.70)$ & 0 & LWS (0.84) & & 8 \\
\hline & & AM17 & & $424(0.97)$ & & $485(0.70)$ & $525(0.29)$ & $561(0.88)$ & 0 & LWS (0.96) & & 8 \\
\hline & & AM18 & & & $457(0.52)$ & $485(0.33)$ & $525(0.46)$ & $561(0.87)$ & 0 & LWS (0.87) & & 9 \\
\hline \multirow[t]{12}{*}{ P. taeniolatus } & Female & TF6 & & $428(0.49)$ & $457(0.89)$ & $491(0.75)$ & $533(0.55)$ & $576(0.95)$ & 18.1 & LWS (0.86) & & 7 \\
\hline & & TF2 & & $428(0.66)$ & $457(0.98)$ & $487(0.84)$ & $528(0.55)$ & $571(0.43)$ & 10.6 & LWS (0.63) & & 7 \\
\hline & & TF1 & & $428(0.49)$ & $457(0.97)$ & $48(0.49)$ & & $571(0.91)$ & 15.1 & LWS (0.98) & $\mathrm{RH} 2 \mathrm{a}(0.82)$ & 10 \\
\hline & & TF4 & & $428(0.48)$ & $457(0.54)$ & & $529(0.88)$ & $571(0.72)$ & 10.6 & LWS (0.91) & & 11 \\
\hline & & TF7 & $379(0.81)$ & & $457(0.47)$ & $487(0.63)$ & $529(0.54)$ & $563(0.73)$ & 6 & LWS (0.93) & & 6 \\
\hline & Male & TM1 & & $428(0.68)$ & $457(0.64)$ & $491(0.59)$ & $533(0.52)$ & $576(0.88)$ & 18.6 & LWS (0.96) & & 7 \\
\hline & & TM3 & & $428(0.71)$ & $457(0.08)$ & $494(0.89)$ & $529(0.59)$ & $571(0.98)$ & 15 & LWS (0.95) & & 7 \\
\hline & & TM8 & & $428(0.59)$ & $457(0.94)$ & $491(0.90)$ & $534(0.49)$ & $576(0.80)$ & 22.6 & LWS (0.95) & & 7 \\
\hline & & TM4 & & $428(0.64)$ & $457(0.91)$ & $486(0.84)$ & & $563(0.98)$ & 3 & LWS (0.98) & $\mathrm{RH} 2 \mathrm{a}(0.96)$ & 9 \\
\hline & & TM6 & & $428(0.42)$ & $457(0.45)$ & $487(0.74)$ & & $571(0.94)$ & 10.7 & LWS (0.97) & $\mathrm{RH} 2 \mathrm{a}(0.87)$ & 9 \\
\hline & & TM5 & $379(0.78)$ & & $457(0.84)$ & $486(0.50)$ & $529(0.57)$ & $563(0.91)$ & 3 & LWS (0.97) & & 6 \\
\hline & & TM2 & $380(0.95)$ & & $457(0.99)$ & $491(0.67)$ & $533(0.87)$ & $576(0.99)$ & 18.1 & LWS (0.99) & & 6 \\
\hline
\end{tabular}

\footnotetext{
${ }^{a} \lambda \max (\mathrm{nm})$ of Visual pigment template that were fitted to the sensitivity curve $\left(R^{2}\right.$ values of the template fits in parentheses). Owing to cone interactions, the sensitivity peaks measured were typically narrower than the fitted pigment templates, resulting in relatively low $R^{2}$ values.

${ }^{b}$ Estimated $A_{2}$ percent in the retina $\left(A_{2}\right.$ percent $=A_{2}$ proportion $\left.\times 100\right)$.

${ }^{\text {CT } T h e ~ v i s u a l ~ p i g m e n t ~ t e m p l a t e ~ t h a t ~ r e s u l t e d ~ i n ~ t h e ~ h i g h e s t ~} R^{2}$ value when fitted to the long-wavelength limb of the spectral sensitivity curve $\left(R^{2}\right.$ value of the template fit in parentheses).

${ }^{\mathrm{d}}$ The visual pigment template which resulted in the second highest $R^{2}$ value when fitted to the long-wavelength limb of the spectral sensitivity curve $\left(R^{2}\right.$ value of the template fit in parentheses).

${ }^{\mathrm{e}}$ The cone pigment subset to which each individual was assigned.
}

detached from rocks, mainly comprising algae and diatoms $[21,26]$.

The frequency of the LWS cone pigment across species was quantitatively correlated with the proportion of long-wavelength reflectance in the color pattern of conspecific males (Figure 4b). As a first-order approximation, the quantum catch of an LWS cone pigment was calculated for the spectral reflectance of the species used in this study. The normalized quantum catch was highest in P. taeniolatus (100\%), lower in M. auratus (80\%) and lowest in M. zebra (17\%).

\section{Color vision in Lake Malawi cichlids}

Spectral sensitivity curves determined using different color background conditions were used to evaluate mechanisms of color vision. Color vision requires the possession of at 
Table 3 Frequency of cone pigment subsets across species and sex

\begin{tabular}{|c|c|c|c|c|c|c|c|}
\hline \multirow[b]{3}{*}{ Subset } & \multirow[b]{3}{*}{ Cones } & \multicolumn{6}{|c|}{ Frequency (\%) } \\
\hline & & \multicolumn{2}{|c|}{ M. zebra } & \multicolumn{2}{|c|}{ M. auratus } & \multicolumn{2}{|c|}{ P. taeniolatus } \\
\hline & & Female (6) & Male (5) & Female (4) & Male (7) & Female (5) & Male (7) \\
\hline 1 & 4 & 50.0 & - & - & - & - & - \\
\hline 2 & 4 & 50.0 & 100.0 & - & - & - & - \\
\hline 3 & 5 & - & - & 50.0 & 28.6 & - & - \\
\hline 4 & 4 & - & - & 25.0 & - & - & - \\
\hline 5 & 3 & - & - & 25.0 & - & - & - \\
\hline 6 & 5 & - & - & - & 14.3 & 20.0 & 28.6 \\
\hline 7 & 5 & - & - & - & 14.3 & 40.0 & 42.9 \\
\hline 8 & 4 & - & - & - & 28.6 & - & - \\
\hline 9 & 4 & - & - & - & 14.3 & - & 28.6 \\
\hline 10 & 4 & - & - & - & - & 20.0 & - \\
\hline 11 & 4 & - & - & - & - & 20.0 & - \\
\hline
\end{tabular}

Frequency of cone pigment subsets in females and males of $M$. zebra, M. auratus and $P$. taeniolatus. Frequency of cone pigment subsets was calculated for each sex and each species on the basis of spectral sensitivity data. The sample size for each of the examined groups is indicated in parentheses.

least two differentially sensitive cones that interact through opponent and nonopponent processes to enable wavelength discrimination [27]. Our results show that $97 \%$ of individuals possessed four or five cone classes. To study cone interactions, we used a multiple-cone mechanism (MCM) model, employing strict criteria (see Methods), to reconstruct spectral sensitivity under different background conditions. To do this, we selected three individual fish that exhibited the most frequent cone subset for a given species. These were subsets 2, 3 and 7, occurring in 73\%, $36 \%$ and $42 \%$ of the $M$. zebra, M. auratus and P. taeniolatus individuals, respectively.

Spectral sensitivity was successfully reconstructed using the MCM model $\left(R^{2}=0.83-0.99\right.$ for all species and background conditions) (Figure 5). Cone interaction was expressed as an additive (nonopponent) or subtractive (opponent) contribution to the modeled spectral sensitivity, and we summarize these cone interactions in Table 4 (see Additional file 4 for more comprehensive information that details the specific coefficients and goodness of fit of the model). Typically, the cone class exhibiting the highest sensitivity for a spectral range contributed positively to the modeled spectral sensitivity, whereas other cone classes contributed either positively (nonopponent) or negatively (opponent) to the modeled spectral sensitivity. The successful reconstruction of spectral sensitivity curves further validated our analysis and the distribution of the cone pigment subsets. Most importantly, we identified and characterized cone interactions representative of retinal neural network processing, essential to color vision.

\section{Discussion}

Pentachromatic color vision in Lake Malawi cichlids

Ninety-seven percent of fish examined in this study employed cone subsets of four or five pigments, with most $M$. auratus and $P$. taeniolatus exhibiting five functional cone classes. The spectral sensitivity of all three species of cichlids was shaped by both opponent and nonopponent cone interactions, and thus our data provide the first comprehensive evidence for pentachromatic color vision in vertebrates. Although the presence of five (or more) cone classes was previously reported in microspectrophotometry studies $[10,28]$, this is the first demonstration that five cone mechanisms were used by a single individual. In this regard, designating the dimensionality of color vision requires the essential evidence that shows not only that the different cone mechanisms participate in spectral sensitivity but also that the different cone mechanisms show multiple neuronal interactions. P. taeniolatus and $M$. auratus showed five distinct cone classes spectrally compressed in a range of $146 \mathrm{~nm}$ (subset 7) and $187 \mathrm{~nm}$ (subset 3), respectively. The spectral compression of this sensitivity provides the basis for extraordinary spectral discrimination, which could be important in visual communication. To better understand how pentachromatic color vision would be beneficial to cichlids, we need to consider factors at play in the visual environment of cichlids where visual communication takes place: (1) the high species diversity of cichlids in Lake Malawi (700-800 species) $[14,25,29],(2)$ the large within-genera variation in the color pattern of fish and the small within-genera variation in their size and shape [30-32] and (3) the prevalence of visual cues driving mate choice [33,34] and intrasexual competition [35]. Visual communication would depend on exquisite sensory performance in this visual environment, since cichlids are continually challenged to make fine-scale discriminations of complex color patterns. This visual system capability would be particularly important in guiding visual behavior related to mate choice, where the detection and recognition of 

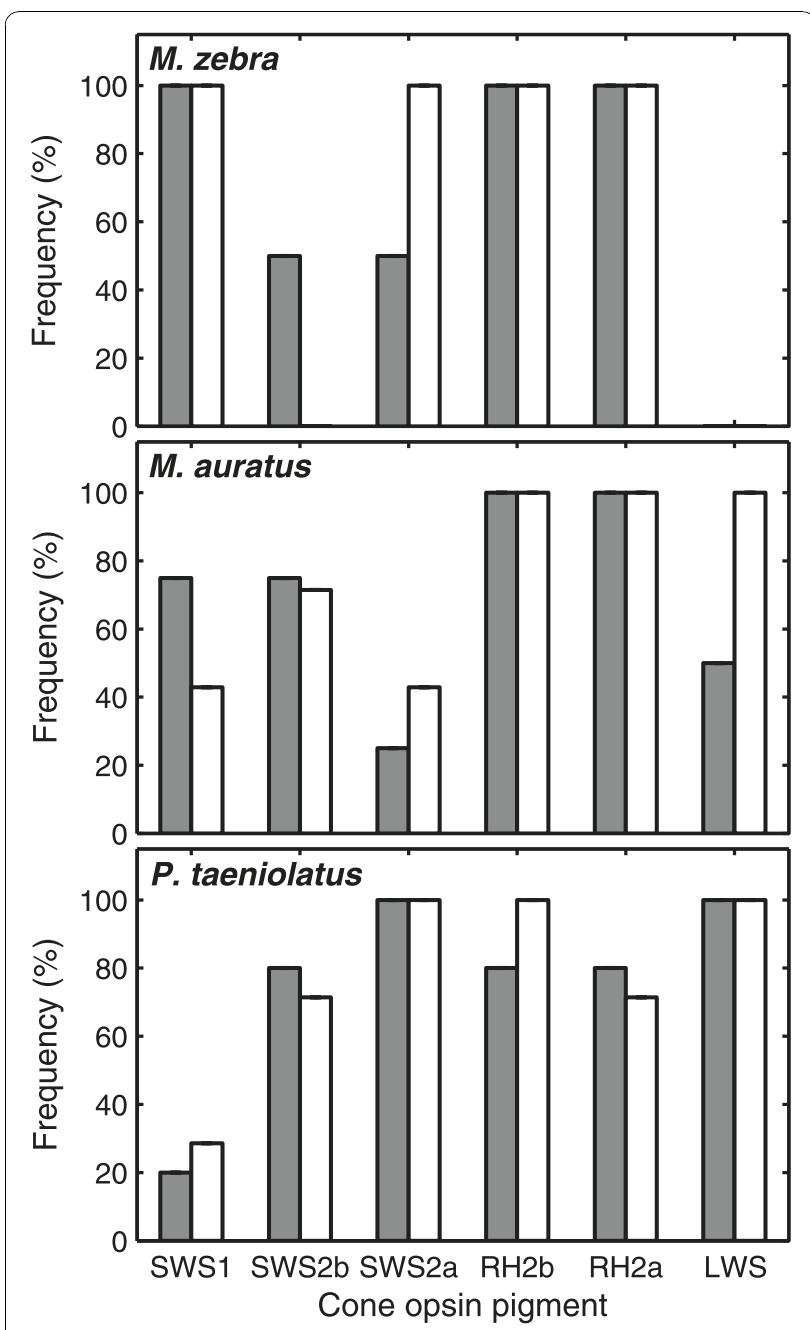

Figure 2 Frequency of cone pigments across sex. Frequency of cone pigments in females (gray) and males (white); M. zebra (top), M. auratus (middle) and P. taeniolatus (bottom). Frequency of cone pigments was calculated for each sex and each species based on spectral sensitivity data. For example, three of four M. auratus females possessed the SWS1 cone pigment in their retinas, thus $75 \%$ of M. auratus females possessed the SWS1 cone pigment. On the other hand, three of seven $M$. auratus males possessed the SWS1 cone pigment in their retina, thus $43 \%$ of $M$. auratus males possessed the SWS1 cone pigment. Sex differences in the frequency of cone pigments in $M$. zebra and $M$. auratus are larger than in $P$. taeniolatus.

conspecific optical signals is critical. These visual adaptations could be fundamental to mate choice fidelity and contribute to the maintenance of biodiversity in the cichlid communities of Lake Malawi.

It is important to point out that our findings differ from the notion that Lake Malawi cichlids primarily exhibit three cone pigments $[10,36]$. Recent reports show a significant variation in the number of opsin genes expressed among Malawi species [37], with several species (one of which is $P$. taeniolatus) expressing more than three cone opsin genes [21]. Furthermore, microspectrophotometry studies have revealed classes of cones in low abundance in the retina of various species that are of unknown significance $[10,36]$. Our study suggests that these rare cone classes contribute to the spectral sensitivity of Lake Malawi cichlids.

\section{Sex differences in the color vision of Lake Malawi cichlids} Our study provides some evidence for sex differences in opsin gene expression, and possibly in spectral sensitivity, for cichlids. While the sample size in electrophysiology studies tends to be low, a possible pattern of differentiation between males and females emerged. The large diversity of cone pigment subsets found in each species was in part qualitatively related to sex differences. This, together with qualitative sex differences in pigment frequency and significant differences in cone opsin gene expression, suggests the possibility for sex differences in the visual system of some Lake Malawi cichlids. Our results suggest that the most prominent sex differences occurred in $M$. auratus. We argue here that males and females may have quite different visual requirements in visual communication scenarios [38-40]. $M$. auratus differs from the two other species in two aspects. (1) M. zebra and P. taeniolatus males hold a permanent territory while females choose among potential mates [41]; M. auratus males, on the other hand, assume a territory only temporarily around breeding events [25]. (2) M. zebra and P. taeniolatus males are conspicuous while the color pattern of females is dull, whereas both female and male $M$. auratus are conspicuous and exhibit colorful, but very different, body patterns [25].

We propose a possible explanation for the observed distribution of sex differences across species. Considering the significant role of visual cues in female mate choice $[33,34]$ and male-male competition for territory [35], both females and territorial males of M. zebra and $P$. taeniolatus would likely benefit from possessing color vision attuned to provide the best recognition ability of conspecific males. In contrast, $M$. auratus males assume a territory only temporarily and thus are less dependent on recognition of conspecific males to increase their mating success. Additionally, not holding a permanent territory potentially allows $M$. auratus males to choose between females. Indeed, in the cichlid Astatotilapia flaviijosephi, males defend territories only during the breeding season and actively choose between females [42]. Furthermore, the investment of M. auratus females in their color pattern adds support to the hypothesis that $M$. auratus males choose between females. Thus, the distribution of sex differences in the visual system across species might be associated with territorial behavior. However, the adaptive role of sexual dimorphism 

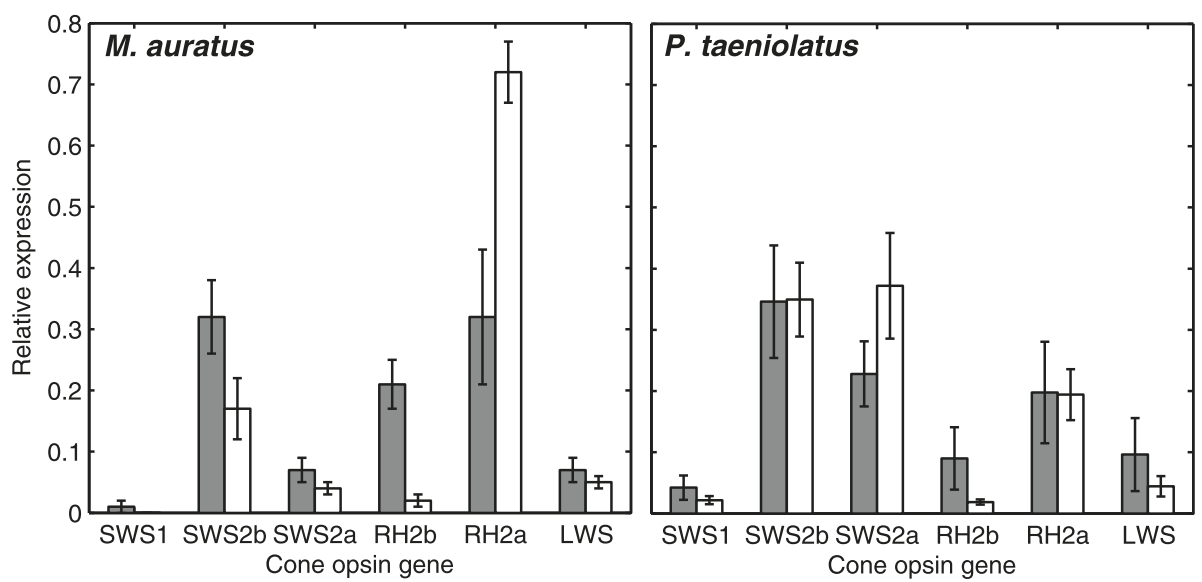

Figure 3 Relative cone opsin gene expression across sex. Relative expression of cone opsin genes (means \pm SEM) in females (gray) and males (white), M. auratus (left) and P. taeniolatus (right). Female and male M. auratus, but not $P$. taeniolatus, differed significantly in the expression of the $\mathrm{RH}_{2} \mathrm{~b}$ and $\mathrm{RH} 2 \mathrm{a}$ opsin genes. See Additional file 2 for detailed $t$-test results and Additional file 3 for primer specifications for cone opsin genes.

in color vision of Lake Malawi cichlids requires further examination.

\section{Adaptive significance of species differences in the color vision of Lake Malawi cichlids}

The variation in cone pigment frequency across species reflects visual adaptations that both enhance the contrast of transparent prey and detect signals important for mate choice, suggesting that both natural selection and sexual selection played a role in shaping the spectral sensitivity of cichlids.

The frequency of the SWS1 cone pigment across species qualitatively correlated with planktivory. UV photoreception mediated by the SWS1 cone pigment enhances the contrast of transparent zooplankton against the water background and thus aids in their detection [43,44]. However, UV sensitivity does not confer any advantage over longer-wavelength sensitivity in the detection of opaque food items such as loose algae. Thus, UV sensitivity is expected to be highly advantageous for the planktivorous $M$. zebra, less advantageous for the omnivorous $M$. auratus and least advantageous for the herbivorous $P$. taeniolatus, which is in agreement with our findings. Thus, the presence of the SWS1 pigment in the retina of cichlids has likely significant adaptive value. In this regard, the expression of the SWS1 opsin gene was recently reported to be highest among species foraging on zooplankton, phytoplankton and algae and lowest among species foraging on fish or benthic invertebrates [21]; however, the relationship between opsin gene expression and spectral sensitivity in cichlids is still largely unknown. UV photoreception is also tightly linked to polarization sensitivity, and this may provide yet greater contrast enhancement of transparent prey [45-47]. Researchers in our lab are currently examining polarization sensitivity in cichlid fishes and its role in visual behavior.

The frequency of the LWS cone pigment across species was quantitatively correlated with the proportion of long-wavelength reflectance in the color pattern of conspecific males. While the possession of the LWS cone pigment by $M$. auratus and $P$. taeniolatus may facilitate the detection of long-wavelength signals of conspecifics, this would not be the case for $M$. zebra that do not have prominent long-wavelength signals, which is in agreement with our findings. Therefore, the presence of the LWS pigment in M. auratus and P. taeniolatus has a significant adaptive value. Interestingly, the detection of UV reflections from the color pattern of these fish species may be mediated through the $\beta$-band of the LWS cone pigment (Figure $4 \mathrm{~b}$ ), thus potentially eliminating the need for the possession of the SWS1 pigment to detect UV signals from conspecifics.

Both natural and sexual selection work sequentially to contribute to the divergence of Lake Malawi rock-dwelling cichlids [16]. In the first episode of cladogenesis, competition for trophic resources resulted in the differentiation of trophic morphology and the diversification of the visual system to allow the utilization of different foraging styles. The correlation of the frequency of the SWS1 cone pigment across species to planktivory (this study), and the recent report that the expression of the SWS1 opsin gene correlates with planktivory [21], support the idea of diversification of the visual system based on competition for trophic resources. In the second episode of cladogenesis, sexual selection contributed to the differentiation of male nuptial coloration and the accompanying diversification of the visual system to 

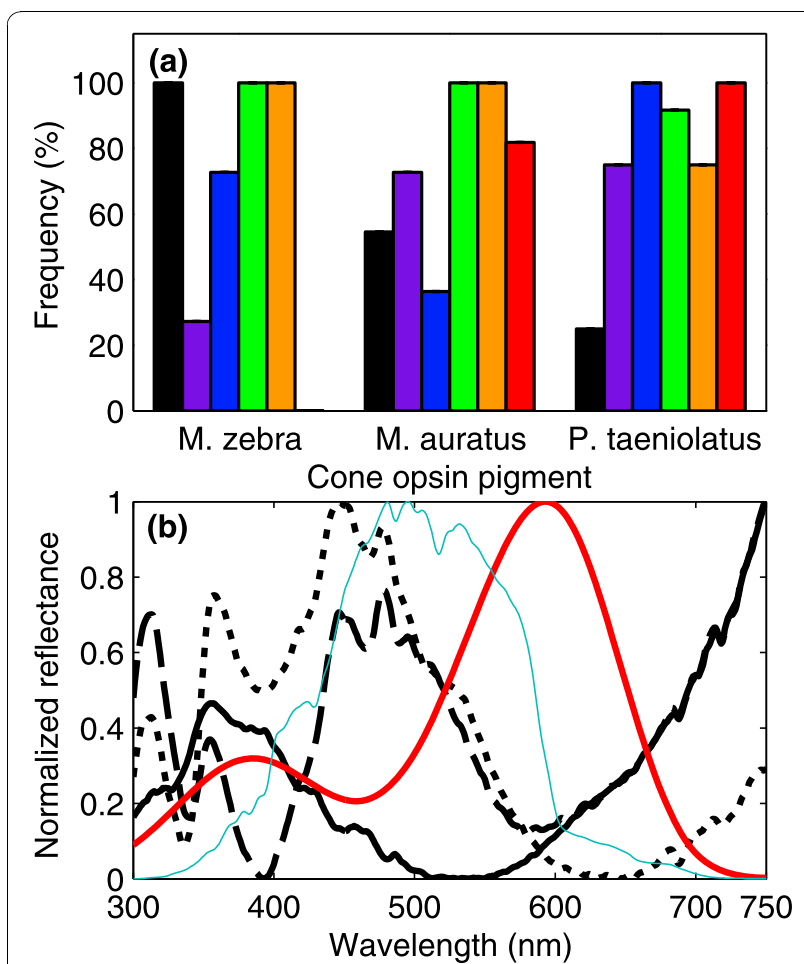

Figure 4 Frequency of cone pigments and spectral reflectance of the color pattern of cichlids. (a) Frequency of cone pigments in M. zebra, M. auratus and P. taeniolatus. Visual pigments: SWS1 (black), SWS2b (violet), SWS2a (blue), RH2b (green), RH2a (orange) and LWS (red). Cone pigment frequency varied across species, with LWS and SWS1 showing the largest frequency variation between species. The frequency of SWS1, SWS2a and LWS differed significantly across species (Fisher's exact test, $P=0.0005, P=0.002$ and $P=0.00001$, respectively). The frequency of SWS2b, RH2a and $\mathrm{RH} 2 \mathrm{~b}$ did not differ significantly across species (Fisher's exact test, $P$ $=0.05, P=0.09$ and $P=1$, respectively). Error rate was set to $\alpha=$ 0.0083 following Bonferroni correction for six hypothesis tests. (b) Average normalized spectral reflectance ( $n=10$; black lines) of the color pattern of M. zebra (solid line), M. auratus (dashed line) and $P$. taeniolatus (dotted line). The normalized absorption of LWS visual pigment (red line) and the normalized sidewelling irradiance measured at 5-m depth in Lake Malawi (blue thin line) are also depicted.

allow high recognition ability of conspecifics. The correlation of the frequency of the LWS cone pigment across species to the proportion of long-wavelength reflectance from male color patterns supports the idea of visual system diversification based on the diverse male nuptial coloration.

Different cichlid species used different cone subsets, with the spectral sensitivity of females being more constrained than that of males. This is suggestive of specific tuning of color vision in females to allow for the best recognition ability of the distinctly colored conspecific males. Previous studies have shown that different cichlid species express diverse opsin gene subsets $[9,21]$, supporting our results. However, a close examination of the different constraints imposed on the visual systems of females and males needs to be undertaken.

The retention of cone opsin genes in Lake Malawi cichlids None of the individuals examined possessed all available six cone pigments ( $\mathrm{RH} 2 \mathrm{a} \alpha$ and $\mathrm{RH} 2 \mathrm{a} \beta$ pooled). However, the large number of pigments utilized and the high diversity in pigment subsets within a species add support for the retention of the complete set of cone opsin genes in Malawi cichlids.

Several factors may contribute to the observed pigment diversity within a species. First, a significant genetic component of opsin expression was reported [48] where individuals with different genetic histories may utilize different pigment subsets. Second, thyroid hormones $(\mathrm{TH})$ are important in vertebrate development and can modulate the opsin gene expression and induce cone loss in fish $[49,50]$. The level of $\mathrm{TH}$ in fish has been associated with environmental stress and subordinance via the effect of cortisol [51,52]. Thus, individuals differing in their stress level or social status may utilize diverse pigment subsets through TH level modulation. Third, social visual cues in fish modulate the activity of GnRH neurons [53]. Since GnRH has been shown to affect retinal neurons [53], it is possible that it may be responsible for changes in opsin gene expression and spectral sensitivity in fish.

\section{Conclusions}

The cichlid model system illustrates that the visual systems of fish may differ across individuals, sexes and species. The large number of available cone opsin genes facilitates this variation in the spectral sensitivity of fish. We show that even rare cone populations and opsin gene expression at low levels contribute to the spectral sensitivity of fish. Our results suggest that the diversification of color vision across species contributes to sensory adaptations that both enhance the contrast of transparent prey and the detection of optical signals of conspecifics. Therefore, both natural and sexual selection may work in concert to shape spectral sensitivity in fish. Taken together, our findings have important implications for understanding the variable nature of fish color vision and the selective forces shaping detection and recognition capabilities.

\section{Methods}

\section{Animals and holding conditions}

Three species of Lake Malawi cichlids were used in this study: Metriaclima zebra (blue top manda), Melanochromis auratus and Protomelas taeniolatus (Old World Exotic Fish, Homestead, FL, USA). M. zebra and $M$. auratus belong to a rock-dwelling evolutionary lineage, 


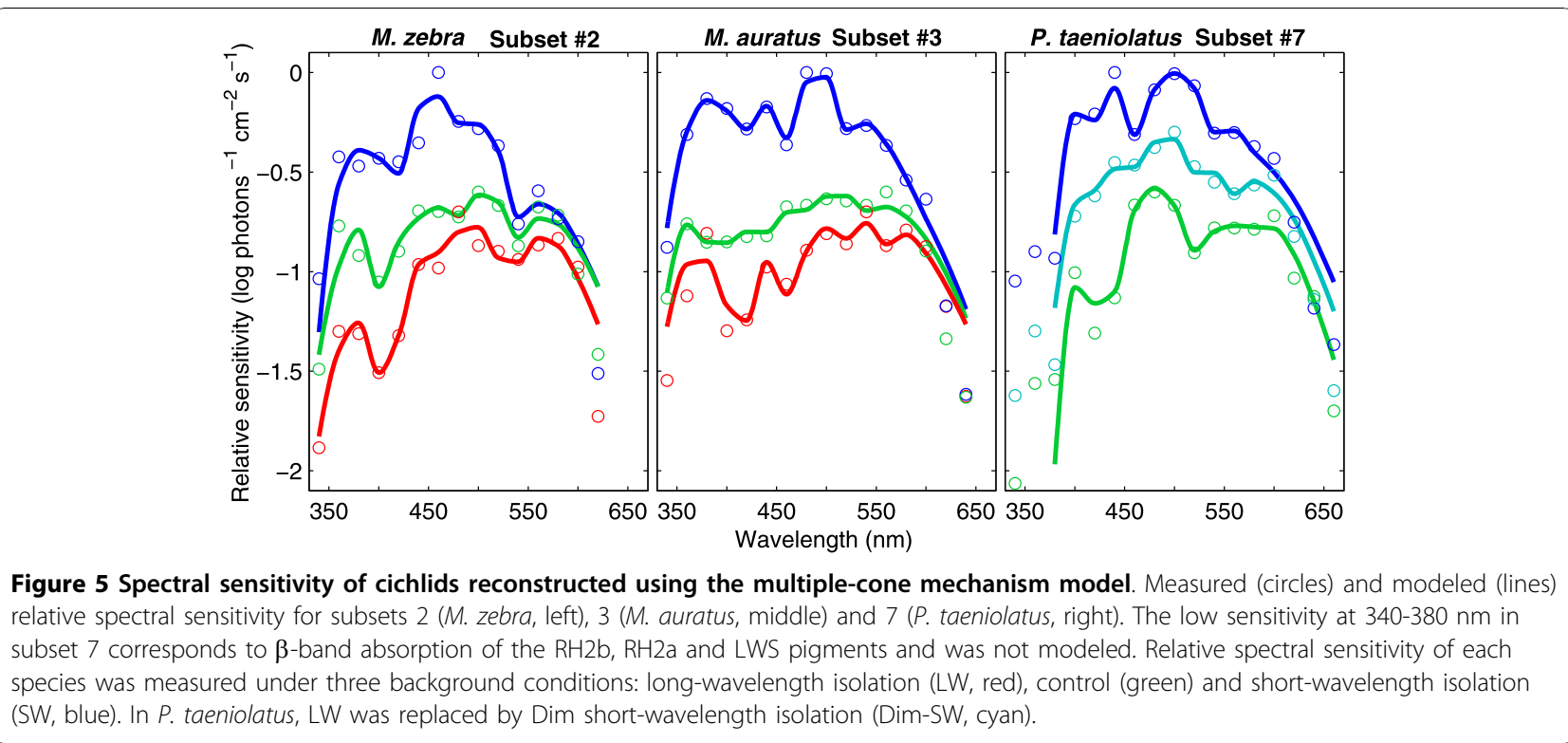

the mbuna, whereas $P$. taeniolatus is a member of the nonmbuna lineage. These species are sexually dimorphic and occur sympatrically in the rocky habitat in Lake Malawi. The males have distinctive nuptial color patterns, and they use the rocky habitat differently with respect to reproductive behavior [25,29]. Adult fish were held in our aquatic facility tanks under a $12 \mathrm{~h}: 12 \mathrm{~h}$

Table 4 Summary of nonopponent and opponent cone interactions

\begin{tabular}{|c|c|c|c|c|c|c|c|}
\hline & \multirow[b]{2}{*}{$\begin{array}{c}\text { Spectral } \\
\text { range }(\mathrm{nm})\end{array}$} & \multicolumn{3}{|c|}{ Single cones } & \multicolumn{3}{|c|}{ Double cones } \\
\hline & & $\mathrm{K}_{\mathrm{swS} 1}$ & $\mathrm{~K}_{\mathrm{swS2b}}$ & $\mathrm{K}_{\text {sws2a }}$ & $\mathrm{K}_{\mathrm{RH} 2 \mathrm{~b}}$ & $\mathrm{~K}_{\mathrm{RH} 2 \mathrm{a}}$ & $\overline{\mathrm{K}_{\mathrm{LWS}}}$ \\
\hline M. zebra & $340-400$ & + & & - & & & \\
\hline \multirow[t]{3}{*}{ (Subset 2) } & $400-480$ & - & & + & - & & \\
\hline & $480-540$ & & & - & + & - & \\
\hline & $540-620$ & & & & - & + & \\
\hline M. auratus & $340-380$ & + & - & & & & \\
\hline \multirow[t]{4}{*}{ (Subset 3) } & $400-440$ & - & + & & & & \\
\hline & $440-480$ & & - & & + & & \\
\hline & $480-540$ & & & & - & + & \\
\hline & $540-640$ & & & & + & & + \\
\hline $\begin{array}{l}P . \\
\text { taeniolatus }\end{array}$ & $380-420$ & & + & & - & & \\
\hline \multirow[t]{4}{*}{ (Subset 7) } & $420-460$ & & & + & - & & \\
\hline & $460-540$ & & - & - & + & & \\
\hline & $540-580$ & & & & & + & + \\
\hline & $580-660$ & & & & - & & + \\
\hline
\end{tabular}

$\mathrm{K}_{\mathrm{SWS} 1}-\mathrm{K}_{\mathrm{LWS}}$ represent the weights of the relative contribution of each cone mechanism to spectral sensitivity used in the multiple-cone mechanism model. Weights can be positive (nonopponent) or negative (opponent). The spectral ranges listed in this table represent discernible peaks (or cone mechanism) in the spectral sensitivity curves, and each peak was fitted by the multiple cone mechanism model. light-dark photoperiod at $25 \pm 1^{\circ} \mathrm{C}$. Facility lighting featured enhanced full spectrum fluorescent lamps (UVBlue actinic and BlueMax lamps; Full Spectrum Solutions, Jackson, MI, USA). All experimental and animal care procedures were approved by Queen's University Animal Care Committee under the auspices of the Canadian Council for Animal Care.

\section{Electroretinogram (ERG) experimental apparatus}

The general design of the optical system and recording apparatus has been described previously [2,54]. Two background channels each with a 250-W quartz-halogen lamp (Osram, Danvers, MA, USA) were used to provide constant background, to which test fish were lightadapted. Long- and short-pass interference filters (Fused Silica, OD 2; Edmund Optics, Barrington, NJ, USA), band-pass interference filters (Edmund Optics), broadband color filters (Schott, Elmsford, NY, USA) and reflective neutral density filters (Edmund Optics), were used to manipulate the spectral irradiance of each background channel. Light from the two background channels was guided to the electrophysiology rig using a bifurcated optical fiber (fused silica, numerical aperture $(\mathrm{NA})=0.22$; Fiberoptic Systems, Simi Valley, CA, USA).

The stimulus channel used a 300-W xenon arc lamp system (Thermo Oriel, Stratford, CT, USA). The optical path consisted of a monochrometer (Instruments SA, Metuchen, New Jersey, USA), Inconel quartz neutral density wedge (0-4.0 neutral density; CVI Melles Griot, Albuquerque, NM, USA), shutter (Uniblitz, Rochester, NY, USA), optical filters to block spectral sidebands and UV lenses to match the numerical aperture of the liquid light pipe (fused silica; NA $=0.55$; Fiberoptic Systems). 
The background and stimulus optical fibers were fitted to a beam splitter to produce a stimulus beam (diameter $0.5 \mathrm{~cm}$ at the plane of the fish eye) contained within the background beam (diameter $1 \mathrm{~cm}$ ). This setup ensured that the chromatically adapted portion of the fish retina was also the one stimulated.

\section{Preparation of fish}

Prior to ERG recordings, fish were immersed in a solution of $150 \mathrm{mg} \mathrm{l}^{-1}$ tricaine methanesulfonate (MS-222) until the fish reached stage IV anesthesia [55]. Intramuscular injections of a general anaesthetic, Maranil $(0.1 \mathrm{mg}$ $\mathrm{g}^{-1}$ body mass) and an immobilizing agent, pancuronium bromide (0.04 $\mathrm{mg} \mathrm{g}^{-1}$ body mass), were administered at several sites. Test fish were then placed in a holding cradle in a Faraday cage. Experimental fish were irrigated with aerated fresh water $\left(20^{\circ} \mathrm{C}\right.$, flow rate $\left.\sim 3 \mathrm{ml} \mathrm{s}^{-1}\right)$, and their body was covered with a moist cloth.

\section{ERG recording procedure}

ERG recordings started at least 1 hour following the onset of the light phase and concluded before the onset of the dark phase to avoid any effects related to circadian rhythm $[2,56,57]$. A glass electrode $(1.5 \mathrm{~mm}$ outer diameter, $1 \mathrm{~mm}$ inner diameter, borosilicate glass; World Precision Instruments, Sarasota, FL, USA) that was pulled to a tip diameter of 80-125 $\mu \mathrm{m}$ (P-97 Flaming/Brown Micropipette puller; Sutter Instruments, Novato, CA, USA) was loaded with saline ( $0.684 \mathrm{M}$ sodium chloride) and inserted into a salinefilled chlorided $\mathrm{AgCl}$ half-cell (A-M systems, Sequim, WA, USA). The electrode tip was positioned using a micromanipulator on the dorsal-nasal surface of the right eye. A ground electrode was attached to the caudal fin and a chlorided-silver reference electrode was placed on the head of the test fish. Fish were chromatically adapted for 1 hour prior to experiments. The stimulus duration was $500 \mathrm{~ms}$ with an interstimulus interval of 5 s. An isolated bioamplifier (ISO-80; World Precision Instruments, Sarasota, FL, USA) amplified the ERG signal and filtered the signal using band-pass filter settings $(5-\mathrm{Hz}$ low-pass, $100-\mathrm{Hz}$ highpass). The amplified signal was analyzed with a 16-bit A/D data acquisition system and Signal 4.0 software (Micro 1401; Cambridge Electronic Design Limited, Cambridge, UK). A custom-designed software analysis module determined the b-wave amplitude (corresponding to the $\mathrm{ON}$ response of bipolar cells) by measuring the potential change between the a-wave and b-wave peaks. Spectral sensitivity was measured in $20-\mathrm{nm}$ increments, from 320 to $700 \mathrm{~nm}$, using a staggered wavelength presentation to prevent adaptation to a spectral region.

\section{Analysis of electroretinograms}

A response versus intensity (RI) curve was generated for each wavelength examined. To determine the sensitivity at a given wavelength, the empirical Naka-Rushton function was least-squares fitted to the RI curve with a slope parameter of $1[58,59]$. The log irradiance level corresponding to half response (LogK) was determined, from which the sensitivity was calculated by taking the reciprocal of this value. Typically, the upper asymptote of the Naka-Rushton function could be reached for all wavelengths. There were a few exceptions at wavelengths shorter than $360 \mathrm{~nm}$ and longer than $600 \mathrm{~nm}$. At these wavelengths, the value of the maximum response parameter $\left(R_{\max }\right)$ was set to that of the neighboring wavelength examined, prior to fitting. A log relative sensitivity curve was constructed by normalizing the $\log$ absolute sensitivity values to the maximum sensitivity. This procedure was repeated for each individual under each of the background conditions.

\section{Background isolation conditions}

Four background conditions were designed and used for isolating cones dominating certain spectral regions. A long-wavelength-isolation condition (LW) was used for isolating cone mechanisms most sensitive to long wavelengths, dim and intense short-wavelength-isolation conditions (Dim-SW and SW) aimed at isolating cone mechanisms most sensitive to short wavelengths and a relatively spectrally flat background condition was used as a control. To design and carefully control the level of light adaptation of the respective cone mechanisms, a quantum catch model was used:

$$
Q_{i}=\int_{300}^{800} A_{i}(\lambda) E_{i}(\lambda) d(\lambda)
$$

where $Q_{i}$ (photons $\mathrm{cm}^{-2} \mathrm{~s}^{-1}$ ) denotes the quantum catch of cone mechanism $i(i=1,2, \ldots, 6), A_{i}(\lambda)$ represents the visual pigment absorption coefficient of cone mechanism $i$ at a wavelength $\lambda(\mathrm{nm})$, and $E_{i}(\lambda)$ denotes the photon irradiance of the background light field at a wavelength $\lambda$.

\section{Characterization of background conditions}

The irradiance provided under the various background conditions was characterized by measuring the spectral irradiance of the background beam. Spectral irradiance was measured using a spectroradiometer (QE65000; Ocean Optics, Dunedin, FL, USA) connected to a 2-m optical fiber (QP600-2-UV/VIS; Ocean Optics) that was fitted with a cosine corrector (CC-3-UV; Ocean Optics). The spectroradiometer utilized a $1024 \times 58$-element 
square silicon CCD (charge-coupled device) array and was configured with a $25-\mu \mathrm{m}$ slit and a variable blaze wavelength grating $\left(\mathrm{HC}-1\right.$, groove density $=300 \mathrm{~mm}^{-1}$; Ocean Optics), resulting in an effective spectral resolution of $1.9 \mathrm{~nm}$ (FWHM) between 200 and $950 \mathrm{~nm}$. The fiber end was held approximately $5 \mathrm{~cm}$ away from the emergence plane of the background beam, ensuring sampling of the entire beam diameter. The spectroradiometer setup was calibrated for absolute irradiance using a NIST (National Institute of Standards and Technology, Gaithersberg, MD, USA) calibrated HalogenDeuterium dual light source (200-1000 nm, DH-2000CAL; Ocean Optics). In cases where spectral variation exceeded the dynamic range of the spectroradiometer and thus a reliable measurement could not be obtained, the irradiance delivered under the background condition was calculated by multiplying the measured output of each light source by the spectral transmission of the filters used in producing the background condition.

\section{Analysis of spectral sensitivity curves \\ 1. Identification of functional cones}

Two criteria were devised for the identification of cone mechanisms. A sensitivity peak was considered to be a cone mechanism if it satisfied the following conditions: (1) the sensitivity peak appeared under at least two background isolation conditions, and (2) the sensitivity peak exhibited changes that were directly related to changes in the spectral composition of the background conditions. For instance, a sensitivity peak in the ultraviolet range (UV; $340-400 \mathrm{~nm}$ ) was identified as a UV cone when sensitivity increased under a short-wavelength isolation background or as the $\beta$-band of midand long-wavelength cones when sensitivity decreased under a short-wavelength isolation background.

\section{Correspondence between visual pigments and cone mechanisms}

To relate visual pigments with cone mechanisms, absorption templates of visual pigments were fitted to spectral sensitivity curves using a least-squares fit. This technique was previously used in numerous studies and repeatedly has been shown to allow for the identification of the cone classes in the retinas of animals [60-62]. In this regard, interactions between different cone classes produce sensitivity peaks that are narrower than the absorption templates of visual pigments, resulting in a somewhat reduced goodness of fit $[60,61]$. Visual pigment absorbance templates [22] were constructed for the opsin genes previously reported in cichlids: Note that the $\lambda_{\max }$ of $\mathrm{A}_{1}$-reconstituted visual pigment is provided in parentheses SWS1 (368 nm), SWS2b (423 nm), SWS2a (456 nm), Rh2b (484 nm), Rh2a a (519 nm), Rh2a $(528 \mathrm{~nm})$ and LWS $(560 \mathrm{~nm})[10,19]$. In the case of $R h 2 a \alpha$ and Rh2a $\beta$, the spectral overlap of the two visual pigment curves necessitated calculating an average $\lambda_{\max }$ of $523 \mathrm{~nm}$. The $532-\mathrm{nm} \lambda_{\max }$ absorption spectrum was used for subsequent analysis and is hereafter referred to as RH2a. To generate visual pigment templates we combined absorption spectra for the $A_{1}$ and $A_{2}$ chromophores $\left(A_{1}\right.$, equations $1,2,4,5 \mathrm{a}, 5 \mathrm{~b} ; A_{2}$, equations $1,4,6 \mathrm{a}, 6 \mathrm{~b}, 8 \mathrm{a}, 8 \mathrm{~b})$ [22]. The proportion of the $\mathrm{A}_{2}$ state was presented using a fraction parameter, $a$ $(0 \leq a \leq 1)$, and therefore the absorption spectra of a given cone type exhibiting an $\mathrm{A}_{2}$ proportion of $a$ was calculated as $\mathrm{A}_{2}(a)=\mathrm{A}_{1} \cdot(1-a)+\mathrm{A}_{2} \cdot a$. The $\lambda_{\max }$ of each cone type exhibits a defined wavelength shift as the $\mathrm{A}_{2}$ proportion changes [63]. This shift was also taken into account when generating the visual pigment templates for varying $A_{2}$ proportions.

Typically, the long-wavelength peak in spectral sensitivity was located between 560 and $600 \mathrm{~nm}$, and thus it could correspond to either the RH2a (523-560 nm; $\lambda_{\text {max }}$ $\mathrm{A}_{1}-\lambda_{\max } \mathrm{A}_{2}$ ) or the LWS (560-626 nm; $\lambda_{\max } \mathrm{A}_{1}-\lambda_{\max } \mathrm{A}_{2}$ ) visual pigments. Therefore, to correlate the long-wavelength peak with a visual pigment absorption curve, it was necessary to determine the $A_{2}$ proportion in the retina of each individual. Visual pigment absorption templates for the RH2a and LWS pigments were fitted to the long-wavelength limb of the spectral sensitivity curve. The least-squares fit was performed while leaving the $\mathrm{A}_{2}$ proportion and a magnitude coefficient unrestricted, allowing the software to find a visual pigment template with an $\mathrm{A}_{2}$ proportion that best describes the long-wavelength limb. Estimating the $\mathrm{A}_{2}$ proportion on the basis of the long-wavelength limb is the best possible approach because (1) the $\lambda_{\max }$ shift between the $A_{1}$ and $A_{2}$ states is largest for long-wavelength-sensitive cones, and (2) the spectral sensitivity is based on one cone class and thus is not affected by opponent interactions. For each individual, the $\mathrm{A}_{2}$ proportion estimate was used for fitting all visual pigment templates to the spectral sensitivity curve. All absorption templates were corrected for the spectral transmission of the fish lens (P. taeniolatus [64]; M. zebra and M. auratus measured [1]).

\section{Modeling cone interactions}

A multiple-cone mechanism (MCM) model was used to determine the relative contribution of each cone class to each spectral sensitivity curve by assigning weights, which can be positive (excitatory) or negative (inhibitory) for each cone mechanism. This "upper envelope" model that was previously used in primates $[65,66]$ and fish [61] assumes that the spectral sensitivity of the eye is determined by the cones that are most sensitive over the spectral region of concern. This linear model takes the general form $S_{\lambda 1, \lambda 2}(\lambda)=\sum k_{i} \cdot A_{i}(\lambda)$, where $S_{\lambda 1}, \lambda 2$ ( $\lambda$ ) denotes the modeled spectral sensitivity in the spectral range enclosed by $\lambda 1$ and $\lambda 2$ while accounting for 
cone interactions; $A_{i}(\lambda)$ represents the absorption of the visual pigment template, corresponding to cone $i(i=1$, $2, \ldots, 6)$ at a wavelength $\lambda(\mathrm{nm})$; and $k_{i}$ denotes the weight representing the contribution of cone $i$. The MCM model was least-squares fitted to the spectral sensitivity curves determined under the various background conditions for each individual separately. The spectral range between two sensitivity notches was set as the $\lambda 1$ - $\lambda 2$ range $[61,65,66]$. For modeling spectral sensitivity, we selected the cone interaction that (1) included the minimum possible number of cones, (2) allowed for the best fit under all background conditions, and (3) ensured the same type of cone interaction (opponent and nonopponent) under all background conditions. To prevent overparameterization of the model, the number of possible cone interactions was restricted to three. That is, the maximum number of free parameters in the model was three, while the number of data points used to fit the model was always larger than three. The weights assigned to each cone, in addition to the $R^{2}$ values (total amount of variance accounted for by the model across the spectrum), were determined. Log relative sensitivity was transformed to percent relative sensitivity and normalized to range between 0 and 1 prior to fitting [67].

\section{Preparation of retinal samples}

Upon completion of ERG recordings, fish were darkadapted for 1 hour and then killed by cervical transection. Under deep red illumination $(>650 \mathrm{~nm})$, both eyes were enucleated and hemisected along an anterior-posterior axis. The neural retina was then dissected free of pigmented epithelium. Each isolated retina was preserved in $0.5 \mathrm{ml}$ of RNAlater (Ambion), stored at $4^{\circ} \mathrm{C}$ for the first 24 hours, and then kept at $-80^{\circ} \mathrm{C}$ until further processing. The sex of the fish was determined using the acetocarmine technique [68,69]. Fish were dissected and their gonads were removed, stained with acetocarmine and viewed under a dissecting microscope to determine the fish sex. All fish were sexually mature adults showing well-developed eggs or sperm and were at least 9 months old. Cichlids typically reach sexual maturity at 6 months from release $[70,71]$.

\section{Relative gene expression by qPCR}

Quantitative real-time RT-PCR (qPCR) was used to quantify the relative levels of mRNA expression corresponding to the various cone opsin genes. Unless specified otherwise, all procedures described below were performed following the manufacturer's protocols. Total RNA was extracted from retinas (Absolutely RNA Miniprep Kit; Agilent Technologies, Santa Clara, CA, USA), and its amount and quality were determined by reading the absorbance at $260 \mathrm{~nm}$ and calculating the absolute 260/280 absorbance ratio using a benchtop spectrophotometer (Cary 300 Bio; Varian, Santa Clara, CA, USA). Total cDNA was synthesized using 250 ng of total retinal RNA and a Superscript III first-strand synthesis SuperMix (Invitrogen, Carlsbad, CA, USA) at $50^{\circ} \mathrm{C}$ for 30 minutes. See Additional file 3 for primer sequences for the amplification of the cDNA opsin genes in cichlids ( $R H 2 a \alpha$ and $R H 2 a \beta$ combined). All primers were analyzed using the Primer-Blast primer design tool (National Center for Biotechnology Information, Bethesda, MD, USA) for product size, melting temperature, guanine-cytosine content (\%) and sequence specificity. The specificity of all primer pairs was tested by amplifying target sequences present within the cDNA synthesized from retinal total RNA. Amplification was carried out in a Mastercycler gradient 5331 (Eppendorf) using the following concentrations: $2.5 \mathrm{mM} \mathrm{MgCl} 2,200$ $\mu \mathrm{M}$ deoxynucleotide triphosphate (dNTP), $100 \mu \mathrm{M}$ forward and reverse primers, $0.05 \mathrm{U}$ GotTaq Flexi DNA polymerase (Promega, Madison, WI, USA), $1 \times$ PCR buffer and $1 \mu \mathrm{l}$ of cDNA template, in a final volume of 25 $\mu \mathrm{l}$. The PCR cycling profile consisted of an initial hold at $92^{\circ} \mathrm{C}$ for 2 minutes, 40 cycles $\left(92^{\circ} \mathrm{C}\right.$ for $25 \mathrm{~s}, 55^{\circ} \mathrm{C}$ for $25 \mathrm{~s}, 72^{\circ} \mathrm{C}$ for $25 \mathrm{~s}$ ), and a final extension at $72^{\circ} \mathrm{C}$ for 5 $\mathrm{min}$. To verify that the amplified product obtained from each primer pair consisted of a single band and was of the correct size, amplified DNA products were separated in a $2.0 \%$ agarose gel $1 \times$ TBE (Tris/Borate/EDTA) buffer, visualized by GelRed on a gel imager (AlphaImager, Cell Biosciences, Santa Clara, CA, USA) and compared with a benchtop 100-bp DNA ladder (Promega).

qPCR analysis of individual retinal cDNA samples was carried out for each opsin gene using Brilliant SYBR green qPCR Master Mix (Agilent Technologies) in a real-time quantitative system MX3000P ${ }^{\mathrm{mm}}$ (Agilent Technologies). Each $25-\mu$ l reaction contained $1 \times$ Brilliant SYBR Green Master Mix, $200 \mathrm{mM}$ quantities of both forward and reverse primers, $0.05 \mu \mathrm{l}$ of ROX passive reference dye and $1 \mu \mathrm{l}$ of four times diluted cDNA. The reaction mix was placed in 96-well nonskirted polypropylene PCR plate and capped with optical strip caps (Agilent Technologies). The plate was briefly centrifuged and eye-inspected for the presence of bubbles. The thermocycle program was $95^{\circ} \mathrm{C}$ for 10 minutes, followed by 40 cycles of $95^{\circ} \mathrm{C}$ for 25 seconds, $55^{\circ} \mathrm{C}$ for 25 seconds and $72^{\circ} \mathrm{C}$ for 25 seconds. Controls included a reaction lacking cDNA template) and a nontranscribed reaction for genomic DNA contamination (No-RT). All samples were run in triplicate, and fractional cycle values $(\mathrm{Cq})$ were averaged. Amplification efficiencies per sample per target were calculated from the slope of the amplification curve in the exponential phase using LinRegPCR 
11.0 software [72]. Relative gene expression was determined for the six opsin genes as a fraction of the total cone opsin genes expressed for an individual [19]:

$$
\frac{T_{g, i}}{T_{\text {all }, i}}=\frac{\left(1+E_{g, i}\right)^{-C q_{g, i}}}{\sum\left(1+E_{g, i}\right)^{-C q_{g, i}}}
$$

where $T_{g, i} / T_{a l l, i}$ is the relative gene expression ratio for gene $g$ normalized by the total cone opsin genes expressed for individual $i, E_{g, i}$ is the amplification efficiency for gene $g$ and individual $i$, and $C q_{g, i}$ is the fractional cycle value for gene $g$ and individual $i$. Finally, relative gene expression was averaged for each species and sex.

\section{Underwater irradiance measurements}

Underwater spectral irradiance at a horizontal line of sight was measured in July 2008 at a near-shore site at Cape Maclear on the northwestern part of the Nankumba Peninsula, Lake Malawi (14 1" 0" S $34^{\circ} 51^{\prime \prime} 0$ " E; local time: 11:00-11:30, GMT +02:00, average solar zenith angle within the water $=25.6^{\circ}$ ). The sampling site, Otter Point, is exposed to wind and wave action and exhibits a rocky bottom that subsides with depth and becomes a sandy bottom at $\sim 15 \mathrm{~m}$ depth [25]. Irradiance was measured using a thermoelectrically cooled spectroradiometer (QE65000; Ocean Optics) connected to a 30-m optical fiber (ZPK600-30-UV/VIS; Ocean Optics) that was fitted with a cosine corrector (CC-3UV; Ocean Optics). See the specifications of the spectroradiometer in the Characterization of background conditions section. Holding the irradiance probe, a SCUBA diver attained position at depths of 5, 10 and 15 $\mathrm{m}$, and readings were saved on a computer placed on a boat (positioned as far as possible and never between the diver and the sun to prevent shading). The spectroradiometer setup was calibrated for absolute irradiance following the same procedure described in the Characterization of background conditions section.

\section{Spectral reflectance measurements}

Spectral reflectance of the color pattern of fish was measured using a spectroradiometer (USB2000; Ocean Optics) connected to one arm of a 2-m bifurcated optical fiber (BIF600-2-UV/VIS; Ocean Optics). The other arm of the fiber was connected to a light source (DH2000-BAL; Ocean Optics). The spectroradiometer utilized a 2048-element linear silicon CCD array and was configured with a $50-\mu \mathrm{m}$ slit and a grating (groove density, $600 \mathrm{~mm}^{-1}$; blaze wavelength, $400 \mathrm{~nm}$; grating 2 , Ocean Optics), resulting in an effective spectral resolution of $2.06 \mathrm{~nm}$ (FWHM) between 200 and $950 \mathrm{~nm}$. The light source integrated two lamps, tungsten-halogen and deuterium, providing a high and spectrally balanced output between 200 and $1000 \mathrm{~nm}$. The common end of the bifurcated fiber was fitted with a flat black reflectance probe exhibiting a 3-mm diameter tip cut at an angle of $45^{\circ}$. Prior to each measurement session, the light source was allowed to warm up for at least $40 \mathrm{~min}$ utes. Then a measurement of a Spectralon diffuse reflectance standard (WS-1-SL; Ocean Optics) was taken as $100 \%$ reflectance, and a dark measurement was taken as zero reflectance. Fish were immersed in a 1:10 clove oil: ethanol solution immediately after capture until the fish reached stage IV anesthesia [55]. Fish were held submerged in lake water, and spectral reflectance was measured at 10 points along the trunk of the fish (one individual per species). Care was given to sealing the reflectance probe against the fish skin to reduce stray light. Readings were acquired and saved on a laptop computer.

To calculate the quantum catch of the LWS cone pigment, we used the spectral radiance reflected from the color pattern of the species studied (equation 1). In this case, however, $E_{\mathrm{i}}(\lambda)$ was substituted by the product of the sidewelling irradiance at a depth of $5 \mathrm{~m}, E_{\mathrm{h}}(\lambda)$ times the spectral reflectance of the color pattern of the fish, $R(\lambda)$. Absorption template for the LWS cone pigment was generated while assuming $\mathrm{A}_{2}$ proportion of 0.5 [22].

\section{Statistical analysis}

To study the effect of sex on the relative opsin gene expression, we performed multiple $t$-tests where an experiment-wise error rate of $5 \%$ was corrected to $0.83 \%$ $(\alpha=0.05 / 6=0.0083)$ following Bonferroni correction for six hypothesis tests [73] that correspond to six opsin genes ( $R H 2 a \alpha$ and $R H 2 a \beta$ were pooled because of genetic and functional similarity $[10,19])$. Prior to performing statistical analyses, the normality of all data was confirmed using the Kolmogorov-Smirnov test, and the homogeneity of variance across treatment groups was confirmed using Cochran's C test [74]. To study the effect of species on the frequency of cone pigments, we performed multiple Fisher's exact tests (two-tailed) with a corrected experimental error $(\alpha=0.0083)$. Statistical analysis was performed using the Statistica ( $t$-test) and $\mathrm{R}$ version 2.11.1 (Fisher's exact test) software.

\section{Additional material}

Additional file 1: Background isolation conditions for spectral sensitivity measurements. (a) The spectral irradiance provided under the various background isolation conditions. Background conditions: long-wavelength isolation (LW, red), control (green), Dim short wavelength (Dim SW, cyan) and short-wavelength isolation (SW, blue). (b) The quantum catches of the six possible cone mechanisms under each condition. Cone pigment: SWS1 (black), SWS2b (violet), SWS2a (blue), RH2b (green), RH2a (orange) and LWS (red). Cone quantum 
catches were calculated while setting the $A_{2} \%$ of cones to 50 for the design of the background conditions.

Additional file 2: Summary of $t$-test results for the examination of the effect of sex on opsin gene expression.

Additional file 3: Primer specifications for cone opsin genes.

Additional file 4: Statistics of cone interactions for the most frequent cone pigment subset of each species.

\section{Abbreviations}

CCD: charge-coupled device; Dim-SW: dim short-wavelength-isolation background condition; ERG: electroretinogram; FWHM: full width half max; $\mathrm{GnRH}$ : Gonadotropin-releasing hormone; SW: short-wavelength-isolation background condition; LW: long-wavelength-isolation background condition; LWS: long wavelength sensitive; MCM: multiple-cone mechanism; NA: numerical aperture; NIST: National Institute of standards and technology; OD: optical density; RH: rhodopsin-like; RI: response versus intensity; SWS: short wavelength sensitive; TH: thyroid hormones; UV: ultraviolet.

\section{Acknowledgements}

We thank Rotem Goldshmid, Prof. Barrie Frost, Dr. Nicholas Roberts, Dr. Shelby Temple, Shyh-Chi Chen, Ilse Dedden, and Dr. Taro Matsumoto for valuable comments. We thank Dr. James Fraser and Dr. Tom Lisney for help in optimizing the ERG experimental apparatus and procedures, Dr. William Nelson and Dr. Nikolaus Troje for suggestions regarding modeling procedures, Dr. Chris Hofmann for providing lens transmission data for cichlids, and Dr. Karen Carleton for qPCR primer sequences and helpful suggestions for gene expression analysis. This research was supported by a Natural Sciences and Engineering Research Council of Canada (NSERC) Discovery Grant, NSERC Research Tools and Instruments Grant, the Canada Research Chair Program, the Canada Foundation for Innovation, and the Ontario Innovation Trust to CWH. SS was supported by an NSERC Vanier Canada Graduate Scholarship. SMG was supported by a NSERC Postdoctoral Fellowship.

\section{Author details}

'Department of Biology, Queen's University, Kingston, ON, K7L 3N6, Canada. ${ }^{2}$ Department of Biology, McGill University, Montreal, QC, H3A 1B1, Canada. ${ }^{3}$ Centre for Neuroscience Studies, Queen's University, Kingston, ON, K7L 3N6, Canada.

\section{Authors' contributions}

SS carried out the design of the experiments, executed the spectral sensitivity measurements, performed all data analysis and participated in writing the manuscript; $\mathrm{CWH}$ participated in the design of the study and writing the manuscript; RLL performed the GPCR gene expression profiling; SMG performed the spectral reflectance measurements. All authors read and approved the final manuscript.

\section{Competing interests}

The authors declare that they have no competing interests.

Received: 14 July 2010 Accepted: 28 October 2010

Published: 28 October 2010

\section{References}

1. Lisney TJ, Studd E, Hawryshyn CW: Electrophysiological assessment of spectral sensitivity in adult Nile tilapia Oreochromis niloticus: evidence for violet sensitivity. J Exp Biol 2010, 213:1453-1463.

2. Parkyn DC, Hawryshyn CW: Spectral and ultraviolet-polarisation sensitivity in juvenile salmonids: A comparative analysis using electrophysiology. J Exp Biol 2000, 203:1173-1191.

3. Yokoyama S, Yokoyama R: Adaptive evolution of photoreceptors and visual pigments in vertebrates. Annu Rev Ecol Syst 1996, 27:543-567.

4. Bowmaker JK: Evolution of vertebrate visual pigments. Vision Res 2008, 48:2022-2041.
5. Collin SP, Knight MA, Davies WL, Potter IC, Hunt DM, Trezise AEO: Ancient colour vision: Multiple opsin genes in the ancestral vertebrates. Curr Biol 2003, 13:R864-R865.

6. Christoffels A, Koh EGL, Chia JM, Brenner S, Aparicio S, Venkatesh B: Fugu genome analysis provides evidence for a whole-genome duplication early during the evolution of ray-finned fishes. Mol Biol Evol 2004, 21:1146-1151.

7. Furutani-Seiki M, Wittbrodt J: Medaka and zebrafish, an evolutionary twin study. Mech Dev 2004, 121:629-637.

8. Meyer A, Schartl M: Gene and genome duplications in vertebrates: the one-to-four (-to-eight in fish) rule and the evolution of novel gene functions. Curr Opin Cell Biol 1999, 11:699-704.

9. Carleton KL, Kocher TD: Cone opsin genes of African cichlid fishes: Tuning spectral sensitivity by differential gene expression. Mol Biol Evol 2001, 18:1540-1550.

10. Parry JWL, Carleton KL, Spady T, Carboo A, Hunt DM, Bowmaker JK: Mix and match color vision: Tuning spectral sensitivity by differential opsin gene expression in Lake Malawi cichlids. Curr Biol 2005, 15:1734-1739.

11. Shand J, Davies WL, Thomas N, Balmer L, Cowing JA, Pointer M, Carvalho LS, Trezise AEO, Collin SP, Beazley LD, Hunt DM: The influence of ontogeny and light environment on the expression of visual pigment opsins in the retina of the black bream, Acanthopagrus butcheri. J Exp Biol 2008, 211:1495-1503.

12. Fryer G, lles TD: The Cichlid Fishes of the Great Lakes of Africa: Their Biology and Evolution Neptune City, NJ: T. F. H. Publications; 1972.

13. Salzburger $W$ : The interaction of sexually and naturally selected traits in the adaptive radiations of cichlid fishes. Mol Ecol 2009, 18:169-185.

14. Turner GF, Seehausen O, Knight ME, Allender CJ, Robinson RL: How many species of cichlid fishes are there in African lakes? Mol Ecol 2001, 10:793-806.

15. Genner MJ, Seehausen O, Lunt DH, Joyce DA, Shaw PW, Carvalho GR, Turner GF: Age of cichlids: new dates for ancient lake fish radiations. Mol Biol Evol 2007, 24:1269-1282.

16. Danley PD, Kocher TD: Speciation in rapidly diverging systems: lessons from Lake Malawi. Mol Ecol 2001, 10:1075-1086.

17. Kocher TD: Adaptive evolution and explosive speciation: the cichlid fish model. Nature Reviews Genetics 2004, 5:288-298.

18. Jordan R, Kellogg K, Juanes F, Stauffer J: Evaluation of female mate choice cues in a group of Lake Malawi mbuna (Cichlidae). Copeia 2003, 181-186.

19. Spady TC, Parry JWL, Robinson PR, Hunt DM, Bowmaker JK, Carleton KL: Evolution of the cichlid visual palette through ontogenetic subfunctionalization of the opsin gene arrays. Mol Biol Evol 2006, 23:1538-1547.

20. Carleton KL, Spady TC, Streelman JT, Kidd MR, McFarland WN, Loew ER: Visual sensitivities tuned by heterochronic shifts in opsin gene expression. BMC Biol 2008, 6:22.

21. Hofmann CM, O'Quin KE, Marshall NJ, Cronin TW, Seehausen O, Carleton KL: The eyes have it: regulatory and structural changes both underlie cichlid visual pigment diversity. PLOS Biol 2009, 7:e1000266.

22. Govardovskii VI, Fyhrquist N, Reuter T, Kuzmin DG, Donner K: In search of the visual pigment template. Vis Neurosci 2000, 17:509-528.

23. Djamgoz MBA, Yamada M: Electrophysiological characteristics of retinal neurons; interactions and functional output. In The Visual System of Fish Edited by: Douglas R, Djamgoz MBA. London: Chapman and Hall; 1990:161-210.

24. Reinthal PN: The feeding-habits of group of herbivorous rock-dwelling cichlid fishes (Cichlidae, Perciformes) from Lake Malawi, Africa. Environ Biol Fishes 1990, 27:215-233.

25. Ribbink AJ, Marsh BA, Marsh AC, Ribbink AC, Sharp BJ: A preliminary survey of the cichlid fishes of rocky habitats in Lake Malawi. S Afr J Zool 1983, 18:149-310.

26. Konings A: Konings's Book of Cichlids and All the Other Fishes of Lake Malawi Neptune, NJ: T.F.H publications; 1990.

27. Hurvich LM: Color Vision Sunderland, MA: Sinauer Associates; 1981.

28. Fuller RC, Fleishman LJ, Leal M, Travis J, Loew E: Intraspecific variation in retinal cone distribution in the bluefin killifish, Lucania goodei. J Comp Physiol A 2003, 189:609-616.

29. Konings A: Lake Malawi Cichlids in their Natural Habitat Germany: Cichlid Press; 1995. 
30. Deutsch JC: Colour diversification in Malawi cichlids: Evidence for adaptation, reinforcement or sexual selection? Biol J Linn Soc Lond 1997 62:1-14.

31. McElroy DM, Kornfield I, Everett J: Coloration in African cichlids: diversity and constraints in Lake Malawi endemics. Neth J Zool 1991, 41:250-268.

32. Stauffer JR, Bowers NJ, Kellogg KA, McKaye KR: A revision of the blue-black Pseudotropheus zebra (Teleostei: Cichlidae) complex from Lake Malawi, Africa, with a description of a new genus and ten new species. Proc Acad Nat Sci Phila 1997, 148:189-230.

33. Couldridge VCK, Alexander GJ: Color patterns and species recognition in four closely related species of Lake Malawi cichlid. Behav Ecol 2002, 13:59-64.

34. Kidd MR, Danley PD, Kocher TD: A direct assay of female choice in cichlids: all the eggs in one basket. J Fish Biol 2006, 68:373-384.

35. Dijkstra PD, Seehausen O, Groothuis TGG: Direct male-male competition can facilitate invasion of new colour types in Lake Victoria cichlids. Behav Ecol Sociobiol 2005, 58:136-143.

36. Jordan R, Kellogg K, Howe D, Juanes F, Stauffer J, Loew E: Photopigment spectral absorbance of Lake Malawi cichlids. J Fish Biol 2006, 68:1291-1299.

37. Carleton $\mathrm{KL}$ : Cichlid fish visual systems: mechanisms of spectral tuning. Integr Zool 2009, 4:75-86.

38. Darwin C: The Descent of Man and Selection in Relation to Sex London: Murray; 1871.

39. Shine R: Ecological causes for the evolution of sexual dimorphism: a review of the evidence. Q Rev Biol 1989, 64:419-461.

40. Slatkin M: Ecological causes of sexual dimorphism. Evolution 1984, 38:622-630.

41. Barlow GW: Mating systems among cichlid fishes. In Cichlid Fishes: Behaviour, Ecology and Evolution. Edited by: Keenleyside MHA. London: Chapman 1991:173-190

42. Werner NY, Lotem A: Choosy males in a haplochromine cichlid: First experimental evidence for male mate choice in a lekking species. Anim Behav 2003, 66:293-298.

43. Browman $\mathrm{HI}$, Novales Flamarique I, Hawryshyn CW: Ultraviolet photoreception contributes to prey search behavior in 2 species of zooplanktivorous fishes. J Exp Biol 1994, 186:187-198.

44. Johnsen S, Widder EA: Ultraviolet absorption in transparent zooplankton and its implications for depth distribution and visual predation. Mar Biol 2001, 138:717-730

45. Novales Flamarique I, Browman HI: Foraging and prey-search behaviour of small juvenile rainbow trout (Oncorhynchus mykiss) under polarized light. J Exp Biol 2001, 204:2415-2422.

46. Sabbah S, Shashar N: Polarization contrast of zooplankton: a model for polarization-based sighting distance. Vision Res 2006, 46:444-456.

47. Shashar N, Hanlon RT, Petz AD: Polarization vision helps detect transparent prey. Nature 1998, 393:222-223.

48. Carleton KL, Hofmann CM, Klisz C, Patel Z, Chircus LM, Simenauer LH, Soodoo N, Albertson RC, Ser JR: Genetic basis of differential opsin gene expression in cichlid fishes. J Evol Biol 2010, 23:840-853.

49. Temple SE, Ramsden SD, Haimberger TJ, Veldhoen KM, Veldhoen NJ, Carter NL, Roth WM, Hawryshyn CW: Effects of exogenous thyroid hormones on visual pigment composition in Coho salmon (Oncorhynchus kisutch). J Exp Biol 2008, 211:2134-2143.

50. Raine JC, Coffin AB, Hawryshyn CW: Systemic thyroid hormone is necessary and sufficient to induce ultraviolet-sensitive cone loss in the juvenile rainbow trout retina. J Exp Biol 2010, 213:493-501.

51. Ejike C, Schreck CB: Stress and social hierarchy rank in Coho salmon. Trans Am Fish Soc 1980, 109:423-426.

52. Pickering AD: Growth and stress in fish production. Aquaculture 1993, 111:51-63.

53. Ramakrishnan S, Wayne NL: Social cues from conspecifics alter electrical activity of gonadotropin-releasing hormone neurons in the terminal nerve via visual signals. Am J Physiol Regul Integr Comp Physiol 2009, 297 R135-R141.

54. Hawryshyn CW, Moyer HD, Allison WT, Haimberger TJ, McFarland WN: Multidimensional polarization sensitivity in damselfishes. J Comp Physiol A 2003, 189:213-220.

55. Jolly DW, Mawdesley-Thomas LE, Bucke D: Anaesthesia of fish. Vet Rec 1972, 91:424-426.
56. Li P, Temple S, Gao Y, Haimberger TJ, Hawryshyn CW, Li L: Circadian rhythms of behavioral cone sensitivity and long wavelength opsin mRNA expression: a correlation study in zebrafish. J Exp Biol 2005 208:497-504

57. Parkyn DC, Hawryshyn CW: Polarized-light sensitivity in rainbow-trout (Oncorhynchus-Mykiss): characterization from multiunit responses in the optic-nerve. J Comp Physiol A 1993, 172:493-500.

58. Dowling JE, Ripps H: Adaptation in skate photoreceptors. J Gen Physiol 1972, 60:698-719.

59. Naka Kl, Rushton WAH: S-potentials from colour units in retina of fish (Cyprinidae). J Physiol (London) 1966, 185:536-555.

60. Hawryshyn CW, Ramsden SD, Betke KM, Sabbah S: Spectral and polarization sensitivity of juvenile Atlantic salmon (Salmo salar): phylogenetic considerations. J Exp Biol 2010, 213:3187-3197.

61. Hughes A, Saszik S, Bilotta J, DeMarco PJ, Patterson WF: Cone contributions to the photopic spectral sensitivity of the zebrafish ERG. Vis Neurosci 1998, 15:1029-1037.

62. Patterson WF, McDowell AL, Hughes A, Bilotta J: Opponent and nonopponent contributions to the zebrafish electroretinogram using heterochromatic flicker photometry. J Comp Physiol A 2002, 188:283-293.

63. Harosi Fl: An analysis of two spectral properties of vertebrate visual pigments. Vision Res 1994, 34:1359-1367.

64. Hofmann CM, O'Quin KE, Marshall NJ, Carleton KL: The relationship between lens transmission and opsin gene expression in cichlids from Lake Malawi. Vision Res 2010, 50:357-363.

65. Kalloniatis M, Harwerth RS: Spectral sensitivity and adaptation characteristics of cone mechanisms under white-light adaptation. J Opt Soc Am A 1990, 7:1912-1928.

66. Sperling $H G$, Harwerth RS: Red-green cone interactions in incrementthreshold spectral sensitivity of primates. Science 1971, 172:180-184.

67. Demarco PJ, Powers MK: Spectral sensitivity of On and Off responses from the optic-nerve of goldfish. Visual Neurosci 1991, 6:207-217.

68. Guerrero RD, Shelton WL: An aceto-carmine squash technique for sexing juvenile fishes. The Progressive Fish Culturist 1974, 36:56.

69. Wassermann GJ, Afonso LOB: Validation of the aceto-caramin technique for evaluating phenotypic sex in Nile tilapia (Oreochromis niloticus) fry. Ciência Rural 2002, 32:133-139.

70. Balon EK: Early ontogeny of Labeotropheus Ahl 1927 (Mbuna, Cichlidae, Lake Malawi) with a discussion on advanced protective styles in fish reproduction and development. Environ Biol Fishes 1977, 2:147-176.

71. Morrison CM, Miyake T, Wright JR: Histological study of the development of the embryo and early larva of Oreochromis niloticus (Pisces: Cichlidae). J Morphol 2001, 247:172-195.

72. Ruijter JM, Ramakers C, Hoogaars WMH, Karlen Y, Bakker O, van den Hoff MJB, Moorman AFM: Amplification efficiency: linking baseline and bias in the analysis of quantitative PCR data. Nucleic Acids Res 2009, 37: e45.

73. Quinn GP, Keough MJ: Experimental Design and Data Analysis for Biologists New York: Cambridge University Press; 2002

74. Underwood AJ: Experiments in Ecology Cambridge, UK: Cambridge University Press; 1997.

doi:10.1186/1741-7007-8-133

Cite this article as: Sabbah et al:: Functional diversity in the color vision of cichlid fishes. BMC Biology 2010 8:133.

\section{Submit your next manuscript to BioMed Central and take full advantage of:}

- Convenient online submission

- Thorough peer review

- No space constraints or color figure charges

- Immediate publication on acceptance

- Inclusion in PubMed, CAS, Scopus and Google Scholar

- Research which is freely available for redistribution 